\title{
Evaluation of High-Dose Daptomycin Versus Vancomycin Alone or Combined with Clarithromycin or Rifampin Against Staphylococcus aureus and $S$. epidermidis in a Novel In Vitro PK/PD Model of Bacterial Biofilm
}

\author{
Ashley D. Hall Snyder • Celine Vidaillac • Warren Rose • \\ John P. McRoberts • Michael J. Rybak \\ To view enhanced content go to www.infectiousdiseases-open.com \\ Received: October 6, 2014 / Published online: December 18, 2014 \\ (c) The Author(s) 2014. This article is published with open access at Springerlink.com
}

\section{ABSTRACT}

Introduction: Medical device infections are associated with significant morbidity and mortality. These difficult-to-treat infections often result in antibiotic failure and resistance. Combination therapy is often required, however, the most optimal combination is unknown. We evaluated the in vitro activity of daptomycin (DAP) or vancomycin (VAN) alone and in combination with rifampin (RIF)

Electronic supplementary material The online version of this article (doi:10.1007/s40121-014-0055-5) contains supplementary material, which is available to authorized users.

A. D. Hall Snyder · J. P. McRoberts · M. J. Rybak ( $($ ) Anti-Infective Research Laboratory, Eugene Applebaum College of Pharmacy and Health Sciences, Wayne State University, 259 Mack Ave., Detroit, MI 48201, USA

e-mail:m.rybak@wayne.edu

C. Vidaillac

CRP Sante', Clinical and Epidemiological

Investigation Center (CIEC), Strassen, Luxembourg

W. Rose

University of Wisconsin School of Pharmacy,

Madison, WI 41620, USA

M. J. Rybak

School of Medicine, Wayne State University, Detroit, USA or clarithromycin (CLA) against strains of Staphylococcus aureus and S. epidermidis grown in biofilm on 3 prosthetic device materials.

Methods: One methicillin-resistant $S$. aureus (MRSA R5266), one heteroresistant vancomycin-intermediate $S$. aureus ( $h$ VISA R3640), and one methicillin-resistant $S$. epidermidis (MRSE R461) strain was evaluated in a CDC biofilm reactor with titanium, Teflon $^{\circledR}$, and steel coupons. Regimens simulated included DAP $10 \mathrm{mg} / \mathrm{kg} /$ day, and VAN $1 \mathrm{~g}$ q12h alone or in combination with RIF $600 \mathrm{mg}$ q24h or CLA $250 \mathrm{mg}$ q12h. Additional regimens including DAP $12 \mathrm{mg} / \mathrm{kg} /$ day or VAN \pm RIF $450 \mathrm{mg}$ q12h were evaluated against the $h$ VISA strain.

Results: DAP + RIF or VAN + RIF demonstrated enhanced activity against R3640 in embedded biofilm (EB) cells in all materials versus DAP or VAN alone $(P \leq 0.040)$. Only DAP + RIF demonstrated sustained bactericidal activity $\left(\geq 3.80 \quad \log _{10} \mathrm{CFU} / \mathrm{cm}^{2}\right.$ reduction from baseline) against EB and planktonic cells of R5266 and EB cells of R461 in all 3 materials. Of interest, CLA did not appear to enhance DAP or VAN killing activities, and the addition of RIF prevented the emergence of resistance to DAP or VAN in all organisms. 
Conclusion: Using an in vitro bacterial biofilm model containing three common prosthetic device materials, DAP + RIF and VAN + RIF were the most effective regimens. DAP + RIF displayed the greatest activity and represents a promising combination to evaluate for treatment of biofilm-associated staphylococcal infections.

Keywords: Biofilm;

Coagulase-negative

Clarithromycin; staphylococci; Combination therapy; Daptomycin; hVISA; MRSA; Prosthetic device; Rifampin; Staphylococcus aureus; Staphylococcus epidermidis; Vancomycin

\section{INTRODUCTION}

Despite advances in bioengineering and the widespread use of antibiotic prophylaxis, medical implant infections represent a significant source of morbidity in the United States [1]. Two of the most common causative agents of perioperative infections are Staphylococcus aureus and coagulase-negative staphylococci (CoNS), in particular $S$. epidermidis [1]. Both species are frequent commensal organisms of the human skin, and insertion of medical implants through the skin may result in the colonization of these devices. Attached to the surface of the implant, bacteria aggregate in a hydrated polymeric matrix forming sessile communities of biofilm, well protected against hostile conditions of the environment, including antimicrobial exposure [2, 3].

Staphylococci spp., especially multidrugresistant Staphylococci spp. organized in biofilm, represent a significant challenge for clinicians making it difficult or impossible to treat with antimicrobial agents, and detachment from the device may result in systemic infections [4]. Daptomycin (DAP) is a potent lipopeptide that has demonstrated rapid and concentration-dependent bactericidal activity against Staphylococci spp. [5]. Although DAP is known to rapidly penetrate the matrix of biofilm, little is known about the pharmacodynamic activity of DAP in biofilmassociated infections to explain the observed reduced bactericidal activity [6]. Various in vitro models have investigated the activity of DAP against staphylococci biofilms, but most of them have specific limitations. The majority of these models evaluate drug activity under static conditions using a unique type of material, or they do not allow for the investigation of the structure of the biofilm secondary to drug exposure [7-10]. We previously modified an existing commercially available biofilm model for pharmacokinetic/pharmacodynamic (PK/ PD) evaluation of the in vitro activity of antimicrobials against mature biofilm of Staphylococci spp. under conditions mimicking human pharmacokinetics [11]. Using this model, we have demonstrated moderate activity of high-dose DAP alone against biofilm embedded methicillin-sensitive $S$. aureus (MSSA) and methicillin-resistant $S$. aureus (MRSA) isolates on polycarbonate coupons. Combining DAP with RIF or CLA appeared promising as a significant increase in killing activity was noted against DAPsusceptible MRSA or MSSA, respectively [11]. Macrolides like azithromycin and CLA have been shown to decrease the production of polysaccharide glycocalyx by bacteria and have demonstrated synergy with other antibiotics against biofilm-embedded organisms [11, 12]. Even in strains with diminished susceptibility, CLA has been shown to eradicate the polysaccharide glycocalyx matrix surrounding MRSA and $S$. epidermidis bacterial colonies, subsequently 
decreasing biofilm formation and increasing drug penetration [11, 13, 14].

The objective of the present study was to quantify the ability of $S$. aureus and $S$. epidermidis with varying antibiotic susceptibility profiles (MRSA, heteroresistant vancomycin-intermediate $S$. aureus [ $h \mathrm{VISA}$, methicillin-resistant $S$. epidermidis [MRSE]) to form biofilms and to evaluate the activity of DAP alone or in combination with RIF and CLA against cells embedded in biofilm on titanium (TT), Teflon ${ }^{\circledR}$ (TE) and steel (ST) coupons.

\section{MATERIALS AND METHODS}

\section{Bacterial Strains}

Two MRSA (R5266 and R3640), including 1 $h$ VISA (R3640) confirmed by population analysis, and 1 MRSE (R461) were selected from the Anti-Infective Research Laboratory collection to be evaluated.

\section{Antimicrobials}

Daptomycin analytical powder was provided by the manufacturer (Cubist Pharmaceuticals, Inc., Lexington, MA, USA). Stock solutions were prepared according to manufacturer's recommendations. Vancomycin (VAN), CLA and RIF were purchased form Sigma-Aldrich (St. Louis, MO, USA). CLA and RIF were reconstituted following Clinical Laboratory Standards Institute (CLSI) guidelines using methanol and prepared freshly prior to each experiment [15].

\section{Media}

Tryptic Soy broth supplemented with $1 \%$ glucose (gSTSB) and 1/10th gSTSB were used for the 24- and 16-h conditioning phase, respectively, to facilitate biofilm formation. Mueller-Hinton broth (MHB II; Difco, Detroit, MI, USA) supplemented with 25 or $50 \mathrm{mg} / \mathrm{L}$ (SMHB II) of calcium for in vitro experiments using VAN or DAP, respectively, and $12.5 \mathrm{mg} / \mathrm{L}$ magnesium. Colony counts were determined using Tryptic Soy Agar (TSA; Difco, Detroit, MI, USA) plates.

\section{Susceptibility Testing}

Susceptibility testing of all antimicrobials to determine minimum inhibitory concentrations (MIC) and minimum bactericidal concentrations (MBC) was performed in duplicate by broth microdilution at $\sim 5 \times 10^{5}$ colony-forming unit (CFU)/mL in MHB II or SMHB II according to Clinical and CLSI guidelines [15]. Biofilm MICs (MBIC) of all antimicrobials were performed using the pinlid method as previously described [16]. Drugcontaining plates at threefold the organism MIC were used to screen for changes in susceptibility.

\section{In Vitro PK/PD Model}

Isolates were grown on TSA plates incubated at $37^{\circ} \mathrm{C}$ for $24 \mathrm{~h}$ and then suspended in normal saline to reach a concentration equivalent to a $0.5 \mathrm{McFarland}$. The in vitro model consisted of a previously described CDC biofilm reactor (CBR) model (BioSurfaces Technologies, Bozeman, MT, USA), which we modified to run PK/PD, simulating human PK to evaluate the in vitro activity of antimicrobials [11, 17, 18]. Briefly, a 40-h biofilm conditioning phase was performed prior to drug therapy initiation and consisted of a $24 \mathrm{~h}$ incubation at $37^{\circ} \mathrm{C}$ in $1 \%$ gSTSB inoculated with the specified organism, followed by $16 \mathrm{~h}$ of a continuous flow with 
1/10th gSTSB performed with peristaltic pumps (Masterflex ${ }^{\circledR}$; Cole-Parmer Instrument Company, Chicago, IL, USA). Upon completion of conditioning and continuous flow phases $\left(T_{0}\right)$, MHB II (SMHB II for DAPcontaining regimens) was used as media for the drug therapy phase, and boluses of antibiotics were injected into the reactor. Each CBR model held 8 rods with 3 coupons each, allowing for 3 different biomaterials (TT, TE and ST) in each rod. The coupons had a surface area of $3.17 \mathrm{~cm}^{2}$. The CBR was placed in a $37^{\circ} \mathrm{C}$ incubator room throughout the procedure. Fresh media were continuously supplied and removed from the compartment along with the drug via a peristaltic pump set to simulate the antibiotic half-lives. Free drug concentrations were used, and simulated regimens for each strain included: DAP10 $\mathrm{mg} / \mathrm{kg} /$ day [target free drug peak concentration $\left(f C_{\max }\right) 11.3 \mathrm{mg} / \mathrm{L}$; free area under the concentration-time curve from 0 to $24 \mathrm{~h}$ ( $\left.f \mathrm{AUC}_{0-24}\right) 83.1 \mathrm{mg} \mathrm{h} / \mathrm{L}$; average half-life, $8 \mathrm{~h}$; protein binding, 92\%] [19], alone or in combination with CLA $250 \mathrm{mg}$ q12h $\left(f C_{\max }\right.$ $1 \mathrm{mg} / \mathrm{L}$; average half-life $3.5 \mathrm{~h}$; protein binding $50 \%$ ) [20], or RIF $600 \mathrm{mg}$ q24h ( $f C_{\max } 3.5 \mathrm{mg} / \mathrm{L}$; average half-life $3 \mathrm{~h}$; protein binding $80 \%$ ) [2123], and VAN $2 \mathrm{~g}$ q12h ( $f C_{\max } 30 \mathrm{mg} / \mathrm{L}$; average half-life $6 \mathrm{~h}$; protein binding 50\%) [24, 25] alone or in combination with CLA $250 \mathrm{mg}$ $\mathrm{q} 12 \mathrm{~h}$ or RIF $600 \mathrm{mg} \mathrm{q} 24 \mathrm{~h}$. For the $h \mathrm{VISA}$ strain, 3 additional regimens were also incorporated: DAP 12 (DAP12) $\mathrm{mg} / \mathrm{kg} /$ day $\left(f C_{\max } \quad 14.7 \mathrm{mg} / \mathrm{L} ; \quad f A U_{0-24} \quad 102.2 \mathrm{mg} \mathrm{h} / \mathrm{L}\right)$, alone and in combination with RIF $450 \mathrm{mg}$ q12h ( $\left.f \mathrm{C}_{\max } 2.9 \mathrm{mg} / \mathrm{L}\right)[26,27]$, and VAN $2 \mathrm{~g}$ q12h in combination with RIF $450 \mathrm{mg}$ q12h. A growth control was run in the absence of drug (simulated half-life $8 \mathrm{~h}$ ), and each regimen was run in duplicate to ensure reproducibility.

\section{Pharmacodynamic Analysis}

One rod was aseptically removed from each model at $0,4,8,24,48$ and $72 \mathrm{~h}$. Each coupon was rinsed with sterile normal saline to remove excess planktonic cells (P). Biofilm-embedded bacteria (BEB) were recovered from the coupons by 3 alternating 60-s cycles of vortexing and sonication at $20 \mathrm{~Hz}$ (Bransonic ${ }^{\circledR}$ 12; Branson Ultrasonic Corporation, Danbury, CT, USA) and a final $60 \mathrm{~s}$ of vortexing as previously described [11]. Recovered biofilm cells were serially diluted in normal saline and spiral plated with an automatic spiral plater (WASP; DW Scientific, West Yorkshire, UK) onto TSA to allow enumeration of viable colonies. Biofilm-embedded cell concentrations (mean and standard deviation in $\mathrm{CFU} / \mathrm{cm}^{2}$ ) were then computed for each coupon. Colonies were read using protocol reader (ProtoCOL; Microbiology International, Frederick, MD, USA). These methods were reliable to a lower limit of detection of $1-$ $\log _{10} \mathrm{CFU} / \mathrm{cm}^{2}$. The total reduction in $\log _{10}$ $\mathrm{CFU} / \mathrm{cm}^{2}$ over $72 \mathrm{~h}$ was determined by plotting time-kill curves based on the number of viable organisms over the time period. Bactericidal activity $\left(99.9 \%\right.$ kill) was defined as a $\geq 3-\log _{10}$ $\mathrm{CFU} / \mathrm{cm}^{2}$ reduction in colony count from initial inoculum. Bacteriostatic activity was defined as $\mathrm{a}<3-\log _{10} \mathrm{CFU} / \mathrm{cm}^{2}$ reduction in colony count from the initial inoculum, and inactivity was defined as no observed reduction in initial inocula. The time to achieve a $99.9 \%$ bacterial load reduction was determined by linear regression (if $r^{2} \geq 0.95$ ) or visual inspection. Therapeutic enhancement of combination regimens was defined as $\geq 2-$ $\log _{10} \mathrm{CFU} / \mathrm{cm}^{2}$ reduction over the most active single agent. 


\section{Pharmacokinetic Analysis}

Pharmacokinetic samples were obtained, through the injection port of each model at the same time points as PD analysis for verification of target antibiotic concentrations. All samples were stored at $-70^{\circ} \mathrm{C}$ until ready for analysis. VAN concentrations were measured by fluorescence polarization immunoassay $\left(\mathrm{TDx}^{\circledR} ;\right.$ Abbott Diagnostics). Interday coefficients of variance (CV\%) were less than 9\% for low, medium and high standards $(7,35$ and $75 \mathrm{mg} / \mathrm{L})$, respectively. Concentrations of RIF were determined by bioassay utilizing Kocuria rhizophila (formerly Micrococcus luteus) ATCC 9341 as previously described [28]. Briefly, 1/4inch holes were punched in agar plates (antibiotic medium 11) pre-swabbed with a 0.5 McFarland suspension of the test organism and filled with $50 \mu \mathrm{L}$ of standards or samples. This assay demonstrated a CV\% of less than 5\% for $2.5,5$, and $10 \mathrm{mg} / \mathrm{L}$ standards. CLA concentrations were measured by bioassay using Bacillus subtilis ATCC 6631 and antibiotic medium 11 following the same procedure. Each standard was tested in duplicate. Intraday CV\% were less than 7\% for 1,2 , and $5 \mathrm{mg} / \mathrm{L}$. Plates were incubated for $18-24 \mathrm{~h}$ at $37^{\circ} \mathrm{C}$ at which time the zone sizes were measured using a protocol reader (Protocol; Microbiology International, Frederick, MD, USA). Concentrations of DAP were validated utilizing high-performance liquid chromatography (HPLC) [29-31]. Briefly, $100 \mu \mathrm{L}$ of samples were processed with $200 \mu \mathrm{L}$ of $0.1 \%$ formic acid in methanol. After centrifugation, supernatant was removed and transferred to an auto-sampler vial for injection. An isocratic buffer consisting of $35 \%$ acetonitrile and $65 \%$ of ammonium phosphate buffer (0.5\%) was run at a flow rate of $1.0 \mathrm{~mL} / \mathrm{min}$. A Nova-Pak C18 column $(3.9 \times 150 \mathrm{~mm}$; Waters Corp., Milford, MA, USA) was used for separation. Standards were prepared over the range of $3.75-50 \mathrm{mg} / \mathrm{L}$, and interday CV\% were less than $11 \%$ for low, medium and high standards, with a standard curve $r^{2}$ of 0.99 .

The half-life $\left(t_{1 / 2}\right)$, areas under the curve (AUC), and $f C_{\max }$ were determined by the trapezoidal method utilizing PK Analyst software (Version 1.10, MicroMath Scientific Software, Salt Lake City, UT, USA).

\section{Resistance}

Susceptibility testing of colonies recovered at 48 and $72 \mathrm{~h}$ was performed according to CLSI M100-S21 guidelines to evaluate changes in MIC values from baseline isolates. Similarly, biofilm MICs were performed to evaluate any changes in MBICs.

\section{Biofilm Quantification}

Capacity of organisms to form biofilm was assessed by the crystal violet method as previously described [32, 33]. Bacterial strains were grown in 96-well polystyrene flat bottom trays for $24 \mathrm{~h}$ using gSTSB, $2 \% \mathrm{NaCl}$ and $50 \mathrm{mg} /$ $\mathrm{L}$ calcium. After incubation, the broth containing free planktonic cells was drained, washed with normal saline and each well was stained with $2 \%$ crystal violet, rinsed with deionized water and dried. Following drying, $33 \%$ (vol/vol) glacial acetic acid was added to resolubilize the dye and break down the biofilm for reading. Adherent presence of biofilm was measured at optical density (OD) 570 using a spectrophotometer. Control strains for low, medium and high biofilm production in this assay were ATCC 12228, 35556 and NRS 101, respectively. 


\section{Scanning Electron Microscopy (SEM)}

Coupons from rods recovered at 0 and $72 \mathrm{~h}$ were evaluated for presence and structure of biofilm by SEM. After removal, coupons were rinsed in normal saline to remove non-adherent cells and immersed in a fixative solution containing $2.5 \%$ glutaraldehyde and $2 \%$ paraformaldehyde in $0.1 \mathrm{M}$ sodium phosphate buffer. Coupons were then dehydrated in a graded ethanol series and carbon coated at $30 \mathrm{~A}$ for 3 min utilizing a SeeVac Conductavac IV sputter coater (Seevac Inc., Pittsburgh, PA, USA). The coupons were imaged using a Hitachi S570 SEM at 2,000 $\times$ magnification and evaluated for the presence and characteristics of biofilm.

\section{Statistical Analysis}

Changes in CFU/mL for planktonic and CFU/ $\mathrm{cm}^{2}$ for biofilm-embedded bacteria at $72 \mathrm{~h}$ were compared by one-way analysis of variance (ANOVA) with Tukey's Post Hoc test. A $P$ value of $\leq 0.05$ was considered significant. All statistical analyses were performed using SPSS Statistical Software (Release 20.0, SPSS Inc., Chicago, IL, USA).

\section{Compliance with Ethics}

This article does not involve any new studies with human or animal subjects performed by any of the authors.

\section{RESULTS}

Organism susceptibilities are displayed in Table 1. All three isolates were susceptible to DAP (MICs and MBCs of $0.25-0.5 \mathrm{mg} / \mathrm{L}$ ), VAN (MIC $1 \mathrm{mg} / \mathrm{L}, \mathrm{MBC}$ ranging from 1 to $4 \mathrm{mg} / \mathrm{L}$ ) and RIF (MIC $<0.0625 \mathrm{mg} / \mathrm{L}, \mathrm{MBC}=0.5 \mathrm{mg} / \mathrm{L})$. In contrast, all strains were resistant to CLA (MIC $>32 \mathrm{mg} / \mathrm{L}$ ). MBICs for all isolates against were two- to four-fold higher than reported MICs. Changes in organism susceptibilities post model experiments are reported in Table 2.

All strains produced biofilm. MRSA 5266 biofilm production was similar to the low biofilm control strain 12228, while $h$ VISA 3640 produced 50\% more than control strain 12228 and $40 \%$ more than MRSA 5266. The CoNS strain (MRSA 461) produced the highest amounts of biofilm with 75 and 50\% higher biofilm production compared to 5266 and 3640, respectively, and quantification most comparable to the medium producing control strain 35556.

The in vitro PK/PD model activities of antimicrobials are displayed in Table 2 and Fig. 1. Table 3 summarizes the observed PK parameters of simulated regimens.

Against MRSA 5266 and MRSE 461 (Fig. 1a, b), only DAP combined with RIF demonstrated therapeutic enhancement, even reaching bactericidal activity and exceeding $4 \log _{10}$ CFU/ $\mathrm{cm}^{2}$ kill (range 4.13-4.38) when using TT, TE and ST. Reduction in the colony counts from baseline $\left(T_{0}\right)$ to $72 \mathrm{~h}$ were significantly greater on TT and ST coupons from baseline $\left(T_{0}\right)$ to $72 \mathrm{~h}$ ( $\Delta 0$ to $72, P \leq 0.032, P \leq 0.024$, respectively) than all other regimens (Fig. 1; Table 2). These reductions were visible on SEM for MRSE 461 displaying fewer cells on TE coupons after therapy with DAP and RIF at $72 \mathrm{~h}$ (Fig. 2a). Although the combination of VAN + RIF did not display significant enhancement against MRSA 5266 versus VAN alone, a $>3 \log _{10}$ CFU/ $\mathrm{cm}^{2}$ reduction (range 3.2-3.82) was noted for this combination against MRSE 461 for TT, TE and ST $(P \leq 0.044)$. Regrowth at $48 \mathrm{~h}$ was correlated with the emergence of resistance to RIF (RIF MIC $>32 \mathrm{mg} / \mathrm{L}$ ) for DAP-containing 


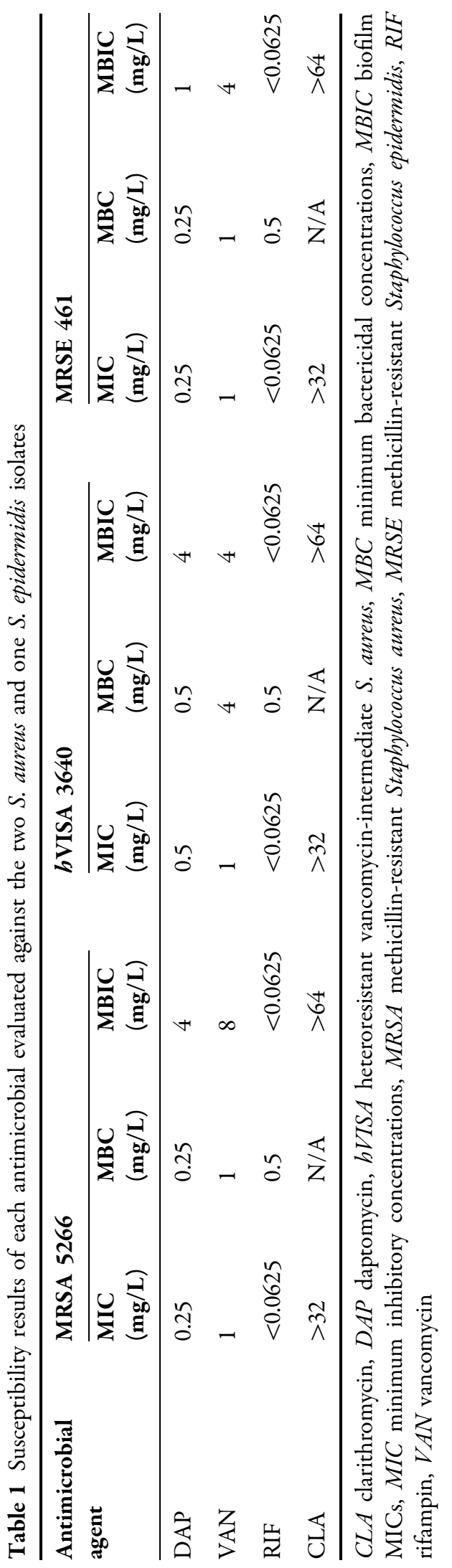

regimen against MRSE 461. Resistance to RIF was noted in the VAN + RIF for 5266, however, it was not correlated with regrowth. Against platonic bacteria (PB) of both MRSE 461 and MRSA 5266, DAP alone or combined with CLA or RIF, and VAN displayed bactericidal activity, however, only the combinations with RIF had sustained activity over $72 \mathrm{~h}$ (data not shown). The addition of CLA to VAN or DAP did not improve killing activity compared to either agent alone against PB (data not shown) or EB of MRSA 5266.

Against $h$ VISA 3640 (Fig. 1c), treatment with DAP10 plus RIF $600 \mathrm{mg}$ daily resulted in therapeutic enhancement as did treatment of VAN plus RIF $450 \mathrm{mg}$ every $12 \mathrm{~h}$ in all materials studied. DAP10 with RIF $600 \mathrm{mg}$ once daily, DAP12 plus RIF $450 \mathrm{mg}$ every $12 \mathrm{~h}$, and VAN combined with RIF $600 \mathrm{mg}$ once daily or $450 \mathrm{mg}$ every $12 \mathrm{~h}$ demonstrated similar killing in all materials studied and appeared more efficacious over DAP10, DAP12, and VAN with or without CLA. Although no regimen achieved sustained bactericidal activity, DAP10 combined with RIF $600 \mathrm{mg}$ was bactericidal at $48 \mathrm{~h}$, and despite regrowth had the greatest absolute reduction in colony count achieving $2.96 \pm 0.52,2.95 \pm 0.04$, and $2.82 \pm 0.59 \log _{10}$ $\mathrm{CFU} / \mathrm{cm}^{2}$ for TT, TE and ST EB, and $6.64 \pm 1.11$ $\log _{10} \mathrm{CFU} / \mathrm{mL}$ for $\mathrm{PB}$ at $72 \mathrm{~h}$, respectively. Against TT coupon EB, DAP10 with RIF $600 \mathrm{mg}$ daily, DAP12 with RIF $450 \mathrm{mg}$ every $12 \mathrm{~h}$ and VAN with RIF $450 \mathrm{mg}$ every $12 \mathrm{~h}$ displayed significant killing over DAP with CLA $(P \leq 0.040)$. Against EB grown on TE, the three regimens above demonstrated significantly more reduction in colony counts than DAP12 monotherapy or DAP10 and VAN alone or in combination with CLA $(P \leq 0.016)$. Reductions in viable EB densities from 0 to $72 \mathrm{~h}$ on TE and ST coupons were significantly greater utilizing DAP10 or DAP12 and RIF compared with 


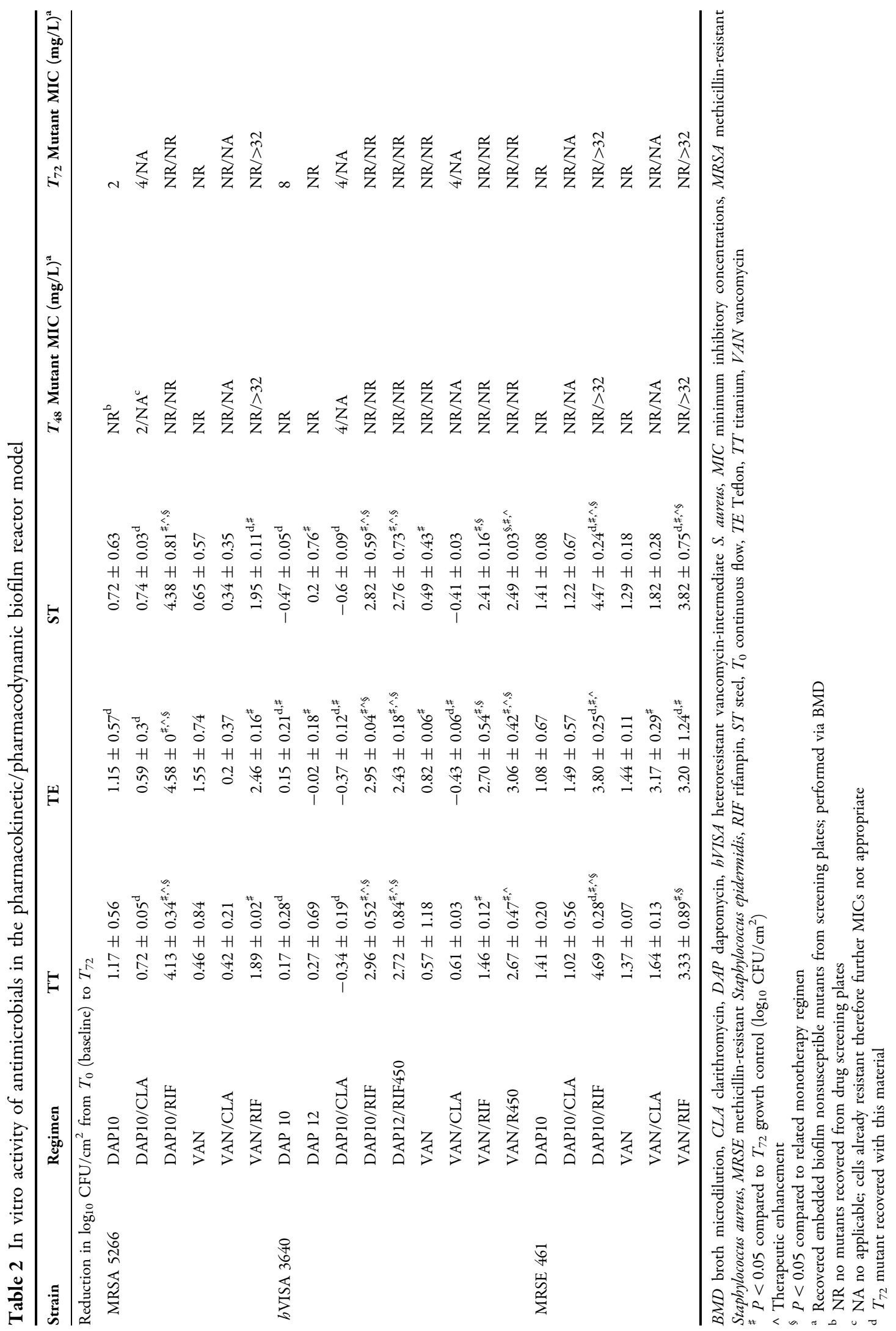



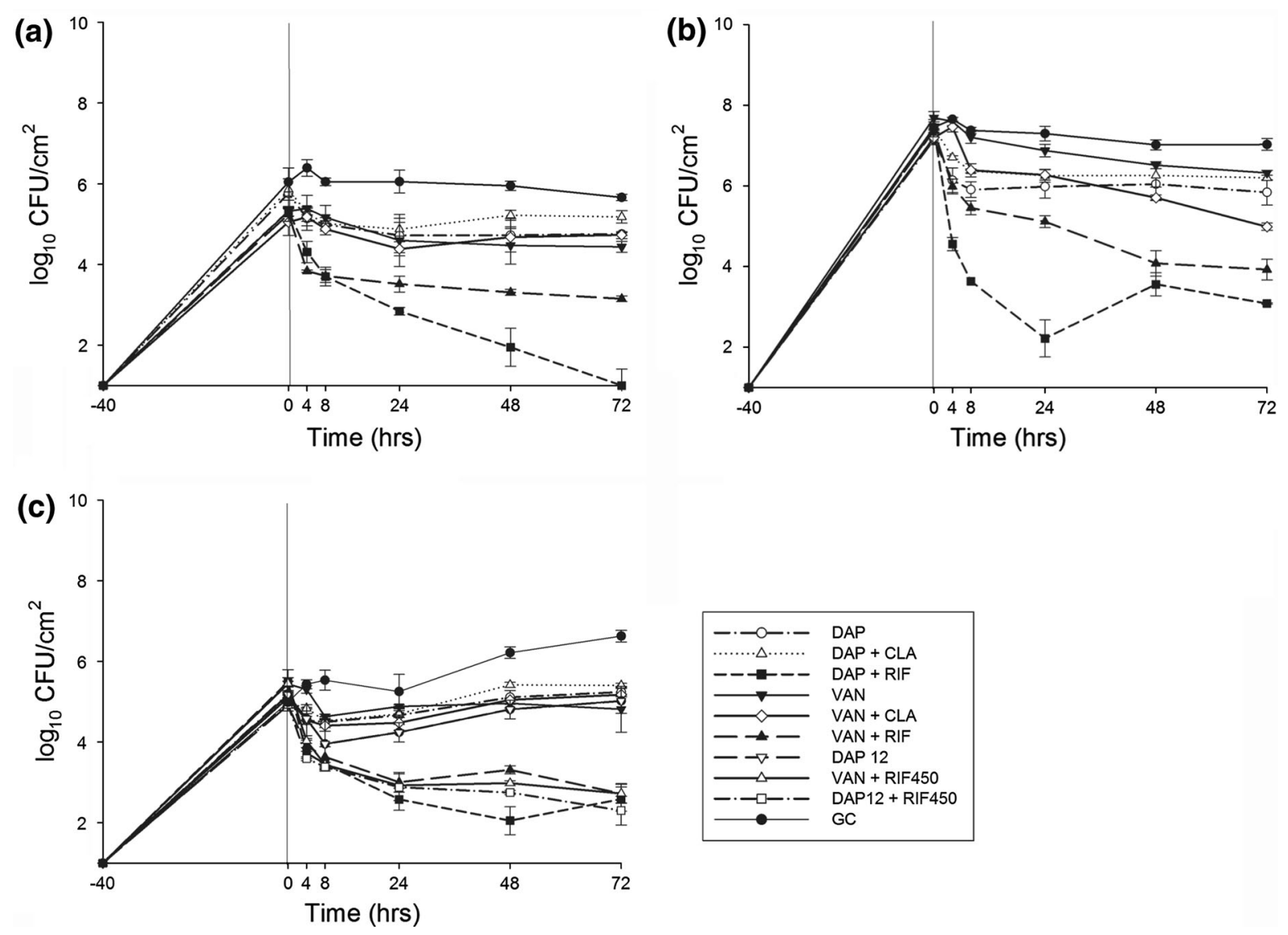

Fig. 1 Activity of DAP and VAN alone and in combination against MRSA 5266 (a), MRSE 461 (b), and bVISA 3640 (c). Error bars denote SD. No significant difference was observed between kill curves obtained on TT, TE and ST coupons, kill curves were combined into 1 graph for clarity purposes. Solid line and filled circle GC, dash-dot line and open circle DAP10, long dash line and inverse open triangle DAP12, dotted line and open triangle DAP + CLA, short dash line and filled square DAP + RIF, dash-dot line

DAP12, DAP10 or VAN with or without CLA $(P \leq 0.028)$. VAN combined with RIF $600 \mathrm{mg}$ daily or $450 \mathrm{mg}$ every $12 \mathrm{~h}$ displayed significantly more killing in TE and ST EB than DAP10 or DAP12 monotherapy and DAP or VAN with CLA $(P \leq 0.032)$ for PB and EB cells. Regrowth with DAP10 monotherapy and DAP with the addition of CLA was correlated to the emergence of non-susceptibility at $72 \mathrm{~h}$ in $\mathrm{EB}$ and PB (Table 2, DAP MIC $=2-8 \mathrm{mg} / \mathrm{L}, \mathrm{MBIC}$

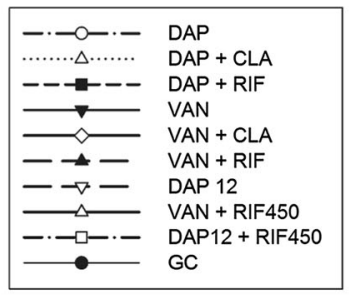

and open square DAP + RIF450, solid line and inverse filled triangle VAN, solid line and opened diamond VAN + CLA, long dash and filled triangle VAN + RIF, solid line and opened triangle VAN + RIF450. CLA clarithromycin, DAP daptomycin, $b$ VISA heteroresistant vancomycin-intermediate $S$. aureus, MRSA methicillin-resistant Staphylococcus aureus, MRSE methicillin-resistant Staphylococcus epidermidis, RIF rifampin, $S D$ standard deviation, $S T$ steel, $T E$ Teflon, TT titanium, $V A N$ vancomycin

8-16 mg/L), however, this was not the case with DAP12 administered alone against EB. Increased MIC to VAN was also observed at $72 \mathrm{~h}$ when combined with CLA, with a change in MIC from 1 to $4 \mathrm{mg} / \mathrm{L}$ in TE EB.

\section{DISCUSSION}

Biofilm infections involving $S$. aureus and $S$. epidermidis are associated with poor patient 
Table 3 Pharmacokinetic parameters of antimicrobials achieved in the PK/PD model

\begin{tabular}{|c|c|c|c|}
\hline Drug, dosage & $f C_{\max }(\mathrm{mg} / \mathrm{L})($ target value $)$ & Half-life (h) (target value) & $f \mathrm{AUC}_{0-24}(\mathrm{mg} \mathrm{h} / \mathrm{L})$ \\
\hline Daptomycin $10 \mathrm{mg} / \mathrm{kg} /$ day & $10.82 \pm 0.53(11.3)$ & $8.64 \pm 0.1(8)$ & $123.1 \pm 5.1$ \\
\hline Daptomycin $12 \mathrm{mg} / \mathrm{kg} /$ day & $14.22 \pm 0.12(14.7)$ & $8.37 \pm 0.46(8)$ & $158.3 \pm 5.0$ \\
\hline Vancomycin $2 \mathrm{~g}$ q12h & $36.6 \pm 1.8(30)$ & $6.19 \pm 0.42(6)$ & $353.7 \pm 4.1$ \\
\hline Rifampin 600 mg daily & $4.35 \pm 0.24(3.5)$ & $2.24 \pm 0.51(3)$ & $6.44 \pm 0.02$ \\
\hline Rifampin $450 \mathrm{mg} \mathrm{q} 12 \mathrm{~h}$ & $4.06 \pm 0.16(2.9)$ & $2.88 \pm 0.12(3)$ & $18.07 \pm 3.21$ \\
\hline Clarithromycin $250 \mathrm{mg} \mathrm{q} 12 \mathrm{~h}^{\mathrm{a}}$ & $1.51 \pm 0.25(1)$ & $2.6 \pm 1.4(3.5)$ & $4.2 \pm 1.8$ \\
\hline
\end{tabular}

Results are expressed as means \pm standard deviations

$f C_{\max }$ maximum free drug concentration, $f A U C_{0-24}$ free area under the concentration-time curve from 0 to $24 \mathrm{~h}, P K / P D$ pharmacokinetics/pharmacodynamics

${ }^{\mathrm{a}} \mathrm{q} 12 \mathrm{~h}$, every $12 \mathrm{~h}$

outcomes, increased hospitalization and treatment costs. These infections are difficult to eradicate due to increased organism resistance and decreased antimicrobial penetration. The 2008 UK MRSA prophylaxis and treatment guidelines recommended glycopeptides with or without adjunctive RIF or sodium fusidate as parenteral therapy for MRSA bone and joint infections [34]. Recently, published Infectious Diseases Society of America (IDSA) guidelines recommend VAN as the preferred treatment for oxacillin-resistant staphylococci prosthetic joint infections with DAP or linezolid considered as alternative therapy [27]. However, these guidelines point out the research gap in alternatives to VAN for management of MRSA and CoNS infection [35]. RIF has been previously used in osteomyelitis and implant-related infection models and has demonstrated activity against staphylococcal biofilms [36-38]. Combination therapy with RIF is recommended for RIF-susceptible joint infections associated with biofilm formation, however, monotherapy is discouraged due to the high rate emergence of resistance. When used in combination with DAP, increased killing has been observed as well as a reduction in the emergence of RIF or DAP resistance $[6,27,36,39,40]$. However, the guidelines fail to specify which antibiotics are most advantageous to eradicate biofilm infection in combination with RIF. Medical devices are constructed from a variety of biomaterials that include polycarbonate, polyurethane, polystyrene, TE, ST and TT that are widely used in osteoarticular prostheses, fixation devices, pacemakers, prosthetic heart valves and vascular grafts [41, 42]. Therefore, it is important to explore the potential of antibiotics used alone and in combination against organisms that are frequently associated with biofilms affecting these materials.

In the current study, we evaluated the killing activity of DAP and VAN against more difficult to eradicate organisms grown on TT, TE and ST materials. As the results indicate, the addition of RIF to DAP and VAN expedited the elimination of biofilm-embedded organisms. The most potent activity was observed with the combination of DAP and RIF in all three organisms, followed by VAN plus RIF. The most profound effect was seen against MRSA, followed by $h$ VISA and CoNS. 

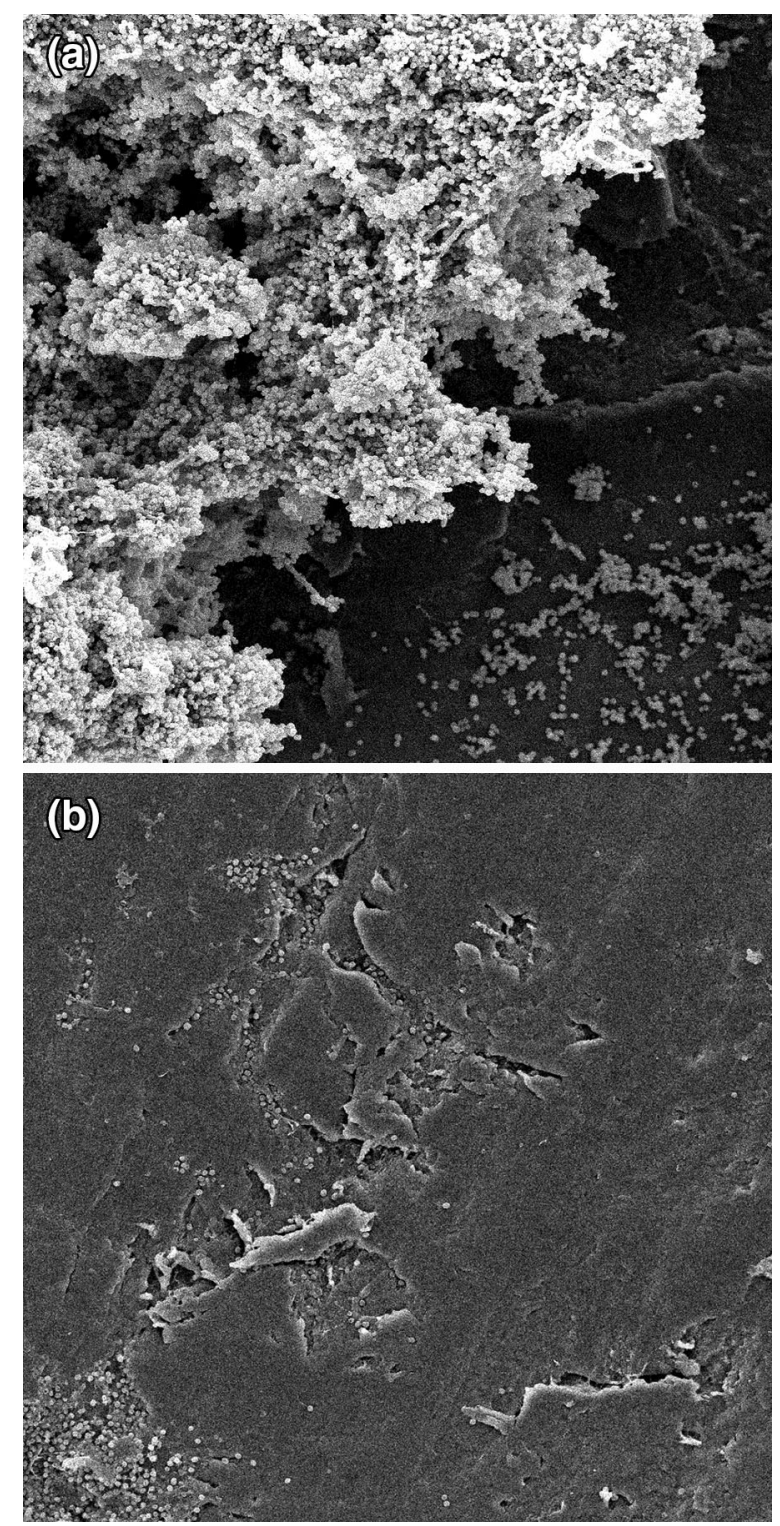

Fig. 2 MRSE 461 embedded biofilm a Teflon coupon prior to antibiotic exposure; $\mathbf{b}$ after $72 \mathrm{~h}$ of DAP + RIF exposure. SEM images are at $1000 \times$ magnification. DAP daptomycin, MRSE methicillin-resistant Staphylococcus epidermidis, RIF rifampin, SEM scanning electron microscopy

Vancomycin has shown varied efficacy in eradication of biofilm infections [43, 44]. Treatment outcomes may vary based on biofilm production and limited VAN penetration into the biofilm matrix [44]. Highdose DAP alone or in combination with RIF has been shown to have an increased effect and to decrease the emergence of resistance in in vitro and in vivo infection models [7, 11, 38]. We have previously demonstrated sustained bactericidal activity in in vitro models utilizing high-dose DAP in combination with CLA against biofilm-embedded MSSA [11]. DAP with RIF displayed similar bacterial eradication against a highly DAP-susceptible MRSA strain against biofilm-embedded bacteria grown on polycarbonate and also prevented the emergence of resistance [11]. DAP nonsusceptibility has been associated with medical device infections, specifically the monotherapy dose of $6 \mathrm{mg} / \mathrm{kg} /$ day has been less effective in eradicating adherent organisms [38, 39, 45]. In the current experiment, increasing the dose to $12 \mathrm{mg} / \mathrm{kg}$ daily of DAP prevented emergence of non-susceptible mutants in the hVISA strain, therefore, increased dosages may be necessary to eradicate organisms recovered from biofilm and prevent further resistance from occurring.

The relatively high rate of emergence of resistance to RIF is consistent with prior data $[11,27,28,37]$. The mechanism of resistance is not well understood, however, rpoB gene mutations and efflux mechanisms are thought to contribute [46]. Development of RIF resistance has previously been observed when used as monotherapy in a catheter-lock model [7]. DAP has been shown to reverse RIF resistance in VAN-resistant Enterococcus faecium. The mechanism is thought to be through potentiating RIF binding to RNA polymerase by increased permeabilization of the outer membrane [46, 47]. In MRSA implant infection models, a reduced incidence of RIF resistance has been found in the presence of DAP [48]. Of note, the addition of RIF prevented development of non-susceptibility to DAP in all isolates evaluated in our study. This finding is consistent with other foreign-body infection 
models, as well as in vivo in humans where DAP mutants have been recovered with DAP monotherapy, but the addition of RIF prevented emergence of DAP and VAN resistance in MRSA [36, 38]. Interestingly, MRSE displayed a higher proclivity toward development of RIF resistance compared to the $h$ VISA and MRSA isolates, although DAP nonsusceptibility was more common in the latter two organisms.

The decreased killing potential of combination therapy against CoNS may be explained by the copious amount of biofilm production as demonstrated by biofilm quantification experiments. There was a trend toward increased killing with the TE material in the hVISA and MRSA organisms, but interestingly not with the CoNS. This may be explained by the amount of biofilm present as well as the varying complexity of the biofilm matrices associated with different biomaterials [49]. One such study demonstrated a higher biofilm forming potential with steel pipes compared to those of polyethylene [49]. To see if an increase in DAP and RIF exposure could further improve killing, therefore, we performed additional model experiments utilizing DAP $12 \mathrm{mg} / \mathrm{kg}$ daily with RIF $450 \mathrm{mg}$ every $12 \mathrm{~h}$ (RIF dose as recommended by Zimmerli et al.) against the hVISA 3640 strain [26]. However, the increase in DAP and RIF exposure did not appear to improve the overall reduction in viable $\mathrm{CFU} / \mathrm{cm}^{2}$ counts.

Previous studies including experiments that we have conducted have shown enhanced killing with the addition of CLA; the mechanism is thought to be through glycocalyx inhibition independent of antimicrobial killing $[11,13,14,50]$. Even in strains with diminished susceptibility, CLA has been shown to eradicate the polysaccharide glycocalyx matrix surrounding MRSA and $S$. epidermidis bacterial colonies, subsequently decreasing biofilm formation and increasing drug penetration $[11,13,14]$. However, these past experiments primarily utilized time-kill methodologies, a single type of material, supratherapeutic CLA concentrations or organisms with lower DAP MICs. This may partially explain the lack of enhanced killing observed with CLA in our present experiments. Of interest, there is also evidence of CLA promoting glycocalyx production in Pseudomonas aeruginosa biofilms when administered at sub-MIC concentrations [51]. Our model simulated bloodstream CLA PKs, and therefore may not fully represent CLA activity due to its high volume of distribution into tissues. Further studies evaluating the role of CLA as a potential agent for combination therapy against biofilm-embedded organisms are warranted.

Strengths of our study include examining more difficult-to-treat organisms such as hVISA and S. epidermidis with higher MICs to DAP than those previously evaluated. Three separate materials (TT, TE and TE) were run simultaneously in the same model, which may control for variables such as testing different materials on different days. Our in vitro biofilm reactor model is unique in that it has been modified to simulate human PKs. Potential limitations in this study included the use of a limited amount of strains and, therefore, the results may not be representative of all staphylococci with varying susceptibility patterns to VAN or DAP. In addition, the use of different materials (TT, TE and ST) within the same biofilm model may have influenced the type of biofilm formation we observed and therefore our results. Another potential limitation was that the drug exposures were carried out over $72 \mathrm{~h}$. Longer antimicrobial exposures may be needed to improve 
penetration into biofilm, improve killing and suppress the emergence of resistance.

In conclusion, the combination of DAP with RIF demonstrated the most effective killing against these three staphylococci isolates in a model of embedded biofilm, followed by VAN in combination with RIF. Further studies evaluating different antimicrobial combinations, additional staphylococci isolates with varying susceptibility patterns and longer durations of antibiotic exposure are warranted.

\section{ACKNOWLEDGMENTS}

This study was supported by an investigator initiated grant from Cubist Pharmaceuticals, Lexington, MA, USA. All named authors meet the ICMJE criteria for authorship for this manuscript, take responsibility for the integrity of the work as a whole, and have given final approval to the version to be published.

Conflict of interest. Michael Rybak has received research support, consulted or participated on speaker bureaus for Cepheid, Cubist, Durata, Forest, Theravance, and Trius and is funded in part by NIH R21A1092055-01.

Ashley Hall Snyder is an employee of Cubist Pharmaceuticals but was a post-doctoral fellow at the time the research was conducted.

Warren Rose has received grant funding and speaking honoraria from Cubist and consults for The Medicines Company.

Celine Vidaillac and John McRoberts declare that they have no conflict of interest.

Compliance with ethics guidelines. This article does not contain any new studies with human or animal subjects performed by any of the authors.
Open Access. This article is distributed under the terms of the Creative Commons Attribution Noncommercial License which permits any noncommercial use, distribution, and reproduction in any medium, provided the original author(s) and the source are credited.

\section{REFERENCES}

1. Trampuz A, Widmer AF. Infections associated with orthopedic implants. Curr Opin Infect Dis. 2006;19(4):349-56.

2. Otto M. Staphylococcal biofilms. Curr Top Microbiol Immunol. 2008;322:207-28.

3. Costerton JW, Stewart PS, Greenberg EP. Bacterial biofilms: a common cause of persistent infections. Science. 1999;284(5418):1318-22.

4. Donlan RM. Biofilms and device-associated infections. Emerg Infect Dis. 2001;7(2):277-81.

5. LaPlante KL, Rybak MJ. Daptomycin-a novel antibiotic against Gram-positive pathogens. Expert Opin Pharmacother. 2004;5(11):2321-31.

6. Stewart PS, Davison WM, Steenbergen JN. Daptomycin rapidly penetrates a Staphylococcus epidermidis biofilm. Antimicrob Agents Chemother. 2009;53(8):3505-7.

7. Raad I, Hanna H, Jiang Y, Dvorak T, Reitzel R, Chaiban G, et al. Comparative activities of daptomycin, linezolid, and tigecycline against catheter-related methicillin-resistant Staphylococcus bacteremic isolates embedded in biofilm. Antimicrob Agents Chemother. 2007;51(5):1656-60.

8. Roveta S, Marchese A, Schito GC. Activity of daptomycin on biofilms produced on a plastic support by Staphylococcus spp. Int J Antimicrob Agents. 2008;31(4):321-8.

9. Smith K, Perez A, Ramage G, Gemmell CG, Lang S. Comparison of biofilm-associated cell survival following in vitro exposure of meticillin-resistant Staphylococcus aureus biofilms to the antibiotics clindamycin, daptomycin, linezolid, tigecycline and vancomycin. Int $\mathrm{J}$ Antimicrob Agents. 2009;33(4):374-8.

10. Presterl E, Hajdu S, Lassnigg AM, Hirschl AM, Holinka J, Graninger W. Effects of azithromycin in combination with vancomycin, daptomycin, 
fosfomycin, tigecycline, and ceftriaxone on Staphylococcus epidermidis biofilms. Antimicrob Agents Chemother. 2009;53(8):3205-10.

11. Parra-Ruiz J, Vidaillac C, Rose WE, Rybak MJ. Activities of high-dose daptomycin, vancomycin, and moxifloxacin alone or in combination with clarithromycin or rifampin in a novel in vitro model of Staphylococcus aureus biofilm. Antimicrob Agents Chemother. 2010;54(10):4329-34.

12. Parra-Ruiz J, Vidaillac C, Rybak MJ. Macrolides and staphylococcal biofilms. Revista espanola de quimioterapia. 2012;25(1):10-6.

13. Yasuda H, Ajiki Y, Koga T, Yokota T. Interaction between clarithromycin and biofilms formed by Staphylococcus epidermidis. Antimicrob Agents Chemother. 1994;38(1):138-41.

14. Sano M, Hirose T, Nishimura M, Takahashi $S$, Matsukawa M, Tsukamoto T. Inhibitory action of clarithromycin on glycocalyx produced by MRSA. J Infect Chemother. 1999;5(1):10-5.

15. Clinical and Laboratory Standards Institute. Performance standards for antimicrobial susceptibility testing. In: Twenty-first Informational Supplement. CLSI document M100S21. Wayne: CLSI; 2011.

16. Ceri H, Olson ME, Stremick C, Read RR, Morck D, Buret A. The Calgary Biofilm Device: new technology for rapid determination of antibiotic susceptibilities of bacterial biofilms. J Clin Microbiol. 1999;37(6):1771-6.

17. Goeres DM, Loetterle LR, Hamilton MA, Murga R, Kirby DW, Donlan RM. Statistical assessment of a laboratory method for growing biofilms. Microbiology. 2005;151(Pt 3):757-62.

18. McLeod BR, Sandvik EL. A biofilm growth protocol and the design of a magnetic field exposure setup to be used in the study of magnetic fields as a means of controlling bacterial biofilms. Bioelectromagnetics. 2010;31(1):56-63.

19. Benvenuto M, Benziger DP, Yankelev S, Vigliani G. Pharmacokinetics and tolerability of daptomycin at doses up to 12 milligrams per kilogram of body weight once daily in healthy volunteers. Antimicrob Agents Chemother. 2006;50(10):3245-9.

20. Biaxin(R), clarithromycin tablets, extended-release tablets and granules for oral suspension [package insert]. North Chicago: Abbott Laboratories; 2003.

21. Rifadin(R), rifampin capsules and injection [package insert]. Kansas City: Merrell Pharmaceuticals, Inc.; 2000.
22. Bennett WM, Aronoff GR, Morrison G, Golper TA, Pulliam J, Wolfson M, et al. Drug prescribing in renal failure: dosing guidelines for adults. Am J Kidney Dis. 1983;3(3):155-93.

23. Peloquin CA, Namdar R, Singleton MD, Nix DE. Pharmacokinetics of rifampin under fasting conditions, with food, and with antacids. Chest. $1999 ; 115(1): 12-8$.

24. Rybak M, Lomaestro B, Rotschafer JC, Moellering R Jr, Craig W, Billeter $M$, et al. Therapeutic monitoring of vancomycin in adult patients: a consensus review of the American Society of Health-System Pharmacists, the Infectious Diseases Society of America, and the Society of Infectious Diseases Pharmacists. Am J Health Syst Pharm. 2009;66(1):82-98.

25. Vancocin(R), capsules and pavules [package insert]. Indianapolis: Eli Lilly and Co; 2000.

26. Zimmerli W, Trampuz A, Ochsner PE. Prostheticjoint infections. $\mathrm{N}$ Engl J Med. 2004;351(16):1645-54.

27. Garrigos C, Murillo O, Euba G, Verdaguer R, Tubau F, Cabellos C, et al. Efficacy of usual and high doses of daptomycin in combination with rifampin versus alternative therapies in experimental foreign-body infection by methicillin-resistant Staphylococcus aureus. Antimicrob Agents Chemother. 2010;54(12):5251-6.

28. Palmer SM, Rybak MJ. Pharmacodynamics of onceor twice-daily levofloxacin versus vancomycin, with or without rifampin, against Staphylococcus aureus in an in vitro model with infected plateletfibrin clots. Antimicrob Agents Chemother. 1996;40(3):701-5.

29. Martens-Lobenhoffer J, Kielstein JT, Oye C, BodeBoger SM. Validated high performance liquid chromatography-UV detection method for the determination of daptomycin in human plasma. J Chromatogr B Analyt Technol Biomed Life Sci. 2008;875(2):546-50.

30. Kullar R, Chin JN, Edwards DJ, Parker D, Coplin WM, Rybak MJ. Pharmacokinetics of single-dose daptomycin in patients with suspected or confirmed neurological infections. Antimicrob Agents Chemother. 2011;55(7):3505-9.

31. Dvorchik BH, Brazier D, DeBruin MF, Arbeit RD. Daptomycin pharmacokinetics and safety following administration of escalating doses once daily to healthy subjects. Antimicrob Agents Chemother. 2003;47(4):1318-23.

32. Christensen GD, Simpson WA, Younger JJ, Baddour LM, Barrett FF, Melton DM, et al. Adherence of 
coagulase-negative staphylococci to plastic tissue culture plates: a quantitative model for the adherence of staphylococci to medical devices. J Clin Microbiol. 1985;22(6):996-1006.

33. Stepanovic S, Vukovic D, Dakic I, Savic B, SvabicVlahovic M. A modified microtiter-plate test for quantification of staphylococcal biofilm formation. J Microbiol Methods. 2000;40(2):175-9.

34. Gould FK, Brindle R, Chadwick PR, Fraise AP, Hill S, Nathwani D, et al. Guidelines (2008) for the prophylaxis and treatment of methicillin-resistant Staphylococcus aureus (MRSA) infections in the United Kingdom. J Antimicrob Chemother. 2009;63(5):849-61.

35. Osmon DR, Berbari EF, Berendt AR, Lew D, Zimmerli W, Steckelberg JM, et al. Diagnosis and management of prosthetic joint infection: clinical practice guidelines by the infectious diseases society of America. Clin Infect Dis. 2013;56(1):e1-25.

36. Saleh-Mghir A, Muller-Serieys C, Dinh A, Massias L, Cremieux AC. Adjunctive rifampin is crucial to optimizing daptomycin efficacy against rabbit prosthetic joint infection due to methicillinresistant Staphylococcus aureus. Antimicrob Agents Chemother. 2011;55(10):4589-93.

37. Olson ME, Slater SR, Rupp ME, Fey PD. Rifampicin enhances activity of daptomycin and vancomycin against both a polysaccharide intercellular adhesin (PIA)-dependent and -independent Staphylococcus epidermidis biofilm. J Antimicrob Chemother. 2010;65(10):2164-71.

38. Lefebvre M, Jacqueline C, Amador G, Le Mabecque V, Miegeville A, Potel $G$, et al. Efficacy of daptomycin combined with rifampicin for the treatment of experimental meticillin-resistant Staphylococcus aureus (MRSA) acute osteomyelitis. Int J Antimicrob Agents. 2010;36(6):542-4.

39. John AK, Baldoni D, Haschke M, Rentsch K, Schaerli $\mathrm{P}$, Zimmerli W, et al. Efficacy of daptomycin in implant-associated infection due to methicillinresistant Staphylococcus aureus: importance of combination with rifampin. Antimicrob Agents Chemother. 2009;53(7):2719-24.

40. Sendi P, Zimmerli W. Antimicrobial treatment concepts for orthopaedic device-related infection. Clin Microbiol Infect. 2012;18(12):1176-84.

41. Long M, Rack HJ. Titanium alloys in total joint replacement-a materials science perspective. Biomaterials. 1998;19(18):1621-39.
42. Holinka J, Pilz M, Hirschl AM, Graninger W, Windhager R, Presterl E. Differential bacterial load on components of total knee prosthesis in patients with prosthetic joint infection. Int J Artif Organs. 2012;35(10):735-41.

43. Evans RC, Holmes CJ. Effect of vancomycin hydrochloride on Staphylococcus epidermidis biofilm associated with silicone elastomer. Antimicrob Agents Chemother. 1987;31(6):889-94.

44. Abdelhady W, Bayer AS, Seidl K, Nast CC, Kiedrowski MR, Horswill AR, et al. Reduced vancomycin susceptibility in an in vitro catheterrelated biofilm model correlates with poor therapeutic outcomes in experimental endocarditis due to methicillin-resistant Staphylococcus aureus. Antimicrob Agents Chemother. 2013;57(3):1447-54.

45. John AK, Schmaler M, Khanna N, Landmann R. Reversible daptomycin tolerance of adherent staphylococci in an implant infection model. Antimicrob Agents Chemother. 2011;55(7):3510-6.

46. Rand KH, Houck HJ, Silverman JA. Daptomycinreversible rifampicin resistance in vancomycinresistant Enterococcus faecium. J Antimicrob Chemother. 2007;59(5):1017-20.

47. Rand KH, Houck H. Daptomycin synergy with rifampicin and ampicillin against vancomycinresistant enterococci. J Antimicrob Chemother. 2004;53(3):530-2.

48. Steenbergen JN, Mohr JF, Thorne GM. Effects of daptomycin in combination with other antimicrobial agents: a review of in vitro and animal model studies. J Antimicrob Chemother. 2009;64(6):1130-8.

49. Yu J, Kim D, Lee T. Microbial diversity in biofilms on water distribution pipes of different materials. Water Sci Technol. 2010;61(1):163-71.

50. Fujimura S, Sato T, Mikami T, Kikuchi T, Gomi K, Watanabe A. Combined efficacy of clarithromycin plus cefazolin or vancomycin against Staphylococcus aureus biofilms formed on titanium medical devices. Int J Antimicrob Agents. 2008;32(6):481-4.

51. Tanaka G, Shigeta M, Komatsuzawa H, Sugai M, Suginaka $H$, Usui $T$. Effect of clarithromycin on Pseudomonas aeruginosa biofilms. Chemotherapy. 2000;46(1):36-42. 